American Journal of Agricultural and Biological Sciences 5 (2): 235-241, 2010

ISSN 1557-4989

(C) 2010 Science Publications

\title{
Effective Factors in Achieving Sustainable Agriculture
}

\author{
${ }^{1}$ Tahereh Sharghi, ${ }^{2}$ Hassan Sedighi and ${ }^{3}$ Abdolreza Roknoddin Eftekhari \\ ${ }^{1}$ Department of Agricultural economics and management, Faculty of agriculture, \\ Payame Noor University, Iran \\ ${ }^{2}$ Department of Agricultural Extension and Education, Faculty of Agriculture, \\ Tarbiat Modares University, Iran \\ ${ }^{3}$ Department of Geography, Faculty of Humanities, Tarbiat Modares University, Iran
}

\begin{abstract}
Problem statement: The indiscriminate use of chemical inputs led to severe degradation of resources in Iran. Therefore, considering the increasing population and growing demand of agricultural products, it seems necessary to achieve a sustainable agriculture. In this study, sustainable agriculture refers to a kind of agriculture which is ecologically appropriate, economically justifiable, and socially desirable. Approach: There were two objectives for this study .The first objective of this study was to identify the effective factors in achieving sustainable agriculture. The second objective was to categorize the effective factors in achieving sustainable agriculture. In this study the Delphi technique has been used. Sustainable agriculture expert researchers of statistical and related issues were 56 scholars selected from the experts in the research centers of Tehran and Yazd provinces. The instruments used in data collection were three series of questionnaires sent to the researchers via email, fax and mail. Results: Findings have shown that the researchers have identified effective factors in achieving sustainable agriculture in Iran as the sections of Infrastructure, policy-making, economy, society, participation, research, extension and education. From the 35 factors exposed to the researchers, the factors of attainment of researches related to sustainable agriculture by agricultural research institutions in Iran, Interaction and participation of researchers, extension educators, farmers and policy-makers of sustainable agriculture, attempt to give priority to those who are the most appropriate from the standpoint of practically creating interactive, logical as well as flexible planning system between different sections dealing with sustainable agriculture have gained the agreement of $100 \%$ researchers. Conclusion: The important conclusion is that the communication between extension, farmers and policymaker should be strengthened. So extension organization should attempt to promote working relationships with research institution, NGOs, agricultural institutions and decision-making systems of policymakers and putting efforts to use participatory approaches in this respect.
\end{abstract}

Key words: Sustainable agriculture, Iranian researchers, effective factors, Delphi method

\section{INTRODUCTION}

Irregular, non-optimized use of agricultural input, especially pesticides and chemical fertilizers, on Iranian lands has resulted in severe damage to water and soil resources, decreased land yield power, environmental pollution, damaged ecological cycle of nature and health problems for humans, livestock and nature. Research results by experts at the Iranian Ministry of Agriculture's Sustainable Agricultural Development Group show that Iran's soil resources suffer less sustainable conditions compared to global and Asian average records and are damaged up to $60 \%$ of resources (Report of Ministry of Agriculture, 2001). This seems to be an alerting trend with regard to the agricultural sector's role in providing food security as well as the increasing population of Iranian society.

A study shows that non-optimized use of fertilizers, including nitrogen fertilizers, not only leads to large quantities of nitrite in vegetables even in tomatoes and cucumbers, but also decreases vitamin $\mathrm{C}$ content in vegetables by up to $26 \%$. These vegetables and fruits form carcinogens in the body, which lead to stomach cancer (Malakooti, 2003). It also shows that

Corresponding Author: Tahereh Sharghi, Department of Agricultural economics and management, Faculty of agriculture, Payame Noor University, Iran 
inappropriate use of chemical fertilizers results in deficiencies and malnutrition in addition to health problems (Malakooti, 2003). This has drawn the attention of the agricultural sector to less use of external input, especially chemicals, as well as more use of methods which lower environmental dangers to a minimum while considering social, economic aspects of production, referred to as methods of sustainable agriculture and environmental protection.

The major challenge for Iranian sustainable agriculture is more appropriate and optimized use of resources, which can be overcome by optimized use of external resources and more appropriate use of internal resources, or a combination of both. Several studies show that farmers have been using more chemical fertilizers than what is proposed (Karami, 1995). Saffari and Pooresfahani's studies on wheat produced by dry farming reveal that the amount of chemical fertilizers used by farmers in such provinces as Isfahan Markazi, Mazandaran, Fars, Khoozestan, Azarbayejan-e Sharghi, Kohguilooyeh and Boyerahmad, Azarbayejan-e Gharbi, Zanjan, Ilam, Gorgan and Gonbad is higher than the optimized level (Report of University of Tehran's Research Deputy, 2000). According to Another study, of the yearly chemical fertilizer consumption of around 2.5 million tons, $50 \%$ are consumed unevenly and/or without regard to plant needs (Malakooti, 2005). Therefore, a movement toward a sustainable agricultural system, one that is economically justifiable, socially appropriate and environmentally nondestructive, forms part of the current policies of the Iranian Ministry of Agriculture. Taking this into consideration, the current study discusses the factors influential in operationalizing sustainable agricultural methods across Iranian fields.

\section{MATERIALS AND METHODS}

The objectives of the study make it a practical research conducted through a field study of a descriptive nature. The statistical population of the study consists of select researchers at organizations in Tehran and Yazd working on sustainable agriculture under the Ministry of Agriculture's Deputy for Agricultural Research and Education in the period between 2005 and 2006. The sample population consists of 56 participants from research organizations in Tehran and Yazd, 9 of whom are from the Yazd National Center for Salinity Research, 14 from the institute of water and soil, 12 from the institute of Pests and Diseases, 4 from the Biotechnology Institute, 8 from the seed correction institute, 3 from the institute for agricultural mechanization and 6 from the institute for the Protection of Plants. Dalkey (1969) states that the reliability of the Delphi method would be more than 0.8 if the number of respondents exceeds 13.

The data has been collected using the Delphi method. Roberts and Dyer (2004), quoting from Stufflebeam, McCormick, Binkerhoff and Nelson, indentify the Delphi method as an effective way to reach a consensus among a group of experts. Roberts and Dyer (2004), quoting from Delp, Thesen, Motiwalla and Seshadri, define the Delphi method as a group process used to request for, collect and manage the respondents toward a consensus (Roling and Pretty, 1996).

The purpose of using the Delphi method here is to prepare a list of factors influential in achieving sustainable agriculture in Iran and categorize them. A panel of sustainable agriculture experts was used for data collection through the Delphi method in three stages: the first stage consisted of preparing an open questionnaire, which eventually yielded a list of factors influential in achieving sustainable agriculture in Iran; the second stage involved preparing a Likert scale questionnaire based on the results of the first stage, which led to a more careful investigation of the opinions of the experts and the third stage involved preparing a questionnaire based on the results of the second stage, which resulted in an obvious consensus of the experts.

The instruments used in data collection were three series of questionnaires sent to the researchers via email, fax and mail.

\section{RESULTS}

The findings of the first stage of the Delphi method show that there are 35 factors influential in achieving stable agriculture in Iran (Table 1). The answering rate for the Delphi method open question, i.e., what are the factors influential in operational zing methods of sustainable agriculture to be used by Iranian farmers?, was $69.6 \%$.

In the second phase (Table 2), response rates of the researchers were $66 / 07 \%$. In this stage the Likert scale range was used for measuring the researchers comment. We examined researchers comments with the Likert range of $1=$ disagree, 2 = rather disagree, $3=$ uncertain, $4=$ rather agree, $5=$ agree.

Based on our results, there are twenty factors with average of more than four. So the experts considered three major factors, including attention to sustainable agriculture by research and extension bodies and interaction among those bodies themselves as well as farmers form the basics of achieving sustainable agriculture. With regard to Iran's conditions. Moreover they assumed it necessary to have a proper interactions between them. 
Table 1: Factors influential in operational zing methods of sustainable agriculture in Iran according to expert opinions; $\mathrm{n}: 39$

\begin{tabular}{|c|c|c|}
\hline No. & Effective factors & responses \\
\hline 1 & Attention of research organizations to required researches in sustainable agriculture & 28 \\
\hline 2 & $\begin{array}{l}\text { Attention of Extension organizations to change content and present extensional methods and make use of cooperation } \\
\text { techniques and opportunities that are proportional and suitable for farmers and also making use of farmer field schools }\end{array}$ & 21 \\
\hline 3 & Presentation of modern patterns in sustainable agriculture & 19 \\
\hline 4 & $\begin{array}{l}\text { Cultural development and give security for achievement in more financial resources for farmers as the result of execution } \\
\text { of sustainable agriculture methods. }\end{array}$ & 19 \\
\hline 5 & $\begin{array}{l}\text { Attention of extensional organizations to provision of required training materials which are proportional to sustainable } \\
\text { agriculture methods. }\end{array}$ & 19 \\
\hline 6 & Presentation and reinforcement of mental and financial cover for farmers & 19 \\
\hline 7 & Effort for education in different levels from elementary farmers to senior managers. & 18 \\
\hline 8 & $\begin{array}{l}\text { Explanation of government's macro policies clearly in order to achieve sustainable agriculture such as adoption of sustainable } \\
\text { agriculture strategy in macro policies. }\end{array}$ & 18 \\
\hline 9 & Effective educations to make farmers powerful & 18 \\
\hline 10 & Orientation of administrative organizations such as ministry of agriculture towards sustainable agriculture in all levels. & 18 \\
\hline 11 & Reinforcement of extension department and settlement of extension workers in farms. & 18 \\
\hline 12 & $\begin{array}{l}\text { Attention of training organizations to train necessary and specialized human resources via university and on-duty educations } \\
\text { in order to achieve sustainable agriculture }\end{array}$ & 13 \\
\hline 13 & Creation and development of productive infrastructures & 12 \\
\hline 14 & Invention of an efficient system to give information to farmers & 12 \\
\hline 15 & $\begin{array}{l}\text { Elimination of economical problems (fairly distribution of wealth, attention to investing in agricultural section, absorbing } \\
\text { of foreign capitals) }\end{array}$ & 12 \\
\hline 16 & Codification or amendment of legal regulations for executing sustainable agriculture methods & 12 \\
\hline 17 & Creation of efficient irrigational systems & 11 \\
\hline 18 & Utilization of motives in order to excite farmers towards sustainable agriculture & 11 \\
\hline 19 & $\begin{array}{l}\text { Establishment of powerful and required organizational structures to achieve sustainable agriculture objectives and } \\
\text { cooperation and coordination among them. }\end{array}$ & 7 \\
\hline 20 & To make state aids meaningful in order to increase motive for using sustainable methods & 7 \\
\hline 21 & Education and explanation of concepts and significance of sustainable agriculture for farmers & 7 \\
\hline 22 & $\begin{array}{l}\text { Presentation of necessary facilities for import, manufacture and production of plants which are compatible } \\
\text { with sustainable methods. }\end{array}$ & 7 \\
\hline 23 & Reform of macro and micro management in agricultural affairs & 7 \\
\hline 24 & Provision and accessibility to machinery and equipments that are proper to sustainable agriculture for farmers & 7 \\
\hline 25 & Valuation of high quality agricultural products which are produced by organic and free of poisonous substances method. & 7 \\
\hline 26 & $\begin{array}{l}\text { Proper marketing and development of high-quality and healthy products export in order to incite farmers to execute } \\
\text { sustainable agriculture methods }\end{array}$ & 6 \\
\hline 27 & Sufficient and proper credits for sustainable production & 6 \\
\hline 28 & Living status, culture, field size and knowledge level of farmers also are key factors in using sustainable agriculture methods & 6 \\
\hline 29 & Living status of consumers and their culture for using healthy products are also important factors. & 4 \\
\hline 30 & $\begin{array}{l}\text { integrating lands and prevention from separation of existing lands cooperation and interaction between researchers, } \\
\text { extension workers, farmers and policy-markers. }\end{array}$ & 4 \\
\hline 31 & Reform of agricultures governmental structure & 3 \\
\hline 32 & Promotion of mechanization. & 3 \\
\hline 33 & Definition and presentation of criteria and indicators for achieving sustainable agriculture & 3 \\
\hline 34 & Formation of a interactive, logical and elastic programming system & 1 \\
\hline 35 & $\begin{array}{l}\text { Effort for being competent from scientific view point (utilization of specialized human resources in state and private } \\
\text { departments, diving facilities such as credits to specialists }\end{array}$ & 1 \\
\hline
\end{tabular}

Table 2: Agreements level with effective factor in achieving sustainable agriculture on the basis of researchers opinions $\mathrm{n}=37$ Effective factors

-Attention of research organizations to required researches in sustainable.

Average

-Attention of extensional organizations to provision of required training materials which are proportional to 4.30 sustainable agriculture methods.

-cooperation and interaction between researchers, extension workers, farmers and policy-markers

$4.22 \quad 0.750$

-Attention of Extension organizations to change content and present extensional methods and make use of of farmer field schools.

-Explanation of government's macro policies clearly in order to achieve sustainable agriculture such as adoption of $\quad 4.22$ 
Table: 2 is continuous

substances method.

-Creation of efficient irrigational systems

-Effort for being competent from scientific view point (utilization of specialized human resources in state and

private departments, diving facilities such as credits to specialists

-Attention of training organizations to train necessary and specialized human resources via university and on-duty

-Reinforcement of extension department and settlement of extension workers in farms

-Presentation of modern patterns in sustainable agriculture

-Promotion of mechanization

- Formation of a interactive, logical and elastic programming system

- Orientation of administrative organizations such as ministry of agriculture towards sustainable agriculture

in all levels.

- Presentation and reinforcement of mental and financial cover for farmers

- Utilization of motives in order to excite farmers towards sustainable agriculture

- Cultural development and give security for achievement in more financial resources for farmers as the result of

- Education and explanation of concepts and significance of sustainable agriculture for farmers

- Living status of consumers and their culture for using healthy products are also important factors.

- Invention of an efficient system to give information to farmers

- Presentation of necessary facilities for import, manufacture and production of plants which are compatible with

- Reform of macro and micro management in agricultural affairs

- Creation and development of productive infrastructures

- Living status, culture, field size and knowledge level of farmers also are key factors in using sustainable

- Provision and accessibility to machinery and equipments that are proper to sustainable agriculture for farmers

- Codification or amendment of legal regulations for executing sustainable agriculture methods

- Elimination of economical problems (fairly distribution of wealth, attention to investing in agricultural section,

- Definition and presentation of criteria and indicators for achieving sustainable agriculture

- Sufficient and proper credits for sustainable production

- To make state aids meaningful in order to increase motive for using sustainable methods

- Reform of agricultures governmental structure

Note: 1 = Disagree, 2 = rather Disagree, 3 = Uncertain, 4 = rather Agree, 5 = Agree

Table 3: Prioritization of acquired agreement levels from viewpoint of studied researchers $n=37$

\begin{tabular}{lll}
\hline Priority & Effective factors & Agreement\% \\
\hline 1 & -Attention of research organizations to required researches in sustainable & 100 \\
& -cooperation and interaction between researchers, extension workers, farmers and policy-markers \\
& -Effort for being competent from scientific view point (utilization of specialized human resources in state \\
and private departments, diving facilities such as credits to specialists & \\
& - Formation of a interactive, logical and elastic programming system \\
& -Attention of extensional organizations to provision of required training materials which \\
& are proportional to sustainable agriculture methods. \\
& -Creation of efficient irrigational systems \\
& -Attention of training organizations to train necessary and specialized human resources via university \\
& and on-duty educations in order to achieve sustainable agriculture \\
& -Presentation of modern patterns in sustainable agriculture \\
& - Elimination of economical problems (fairly distribution of wealth, attention to investing in \\
& agricultural section, absorbing of foreign capitals). \\
& - Presentation of necessary facilities for import, manufacture and production of plants which are \\
& compatible with sustainable methods \\
& -Explanation of government s macro policies clearly in order to achieve sustainable agriculture such \\
& as adoption of sustainable agriculture strategy in macro policies. \\
& -Effort for education in different levels from elementary farmers to senior managers \\
& -Effective educations to make farmers powerful \\
& -Attention of Extension organizations to change content and present extensional methods \\
& and make use of cooperation techniques and opportunities that are proportional and suitable \\
& for farmers and also making use of farmer field schools. \\
-Promotion of mechanization
\end{tabular}


Table: 3 is continuous

- Utilization of motives in order to excite farmers towards sustainable agriculture

- Education and explanation of concepts and significance of sustainable agriculture for farmers

- Cultural development and give security for achievement in more financial resources for farmers

as the result of execution of sustainable agriculture methods.

- Creation and development of productive infrastructures

- Provision and accessibility to machinery and equipments that are proper to sustainable agriculture for farmers

- Living status, culture, field size and knowledge level of farmers also are key factors in using sustainable

agriculture methods

- Codification or amendment of legal regulations for executing sustainable agriculture methods

- Reform of macro and micro management in agricultural affairs

- Definition and presentation of criteria and indicators for achieving sustainable agriculture

-Proper marketing and development of high-quality and healthy products export in order to incite

farmers to execute sustainable agriculture methods

-Reinforcement of extension department and settlement of extension workers in farms

- Presentation and reinforcement of mental and financial cover for farmers

- Invention of an efficient system to give information to farmers

- Establishment of powerful and required organizational structures to achieve sustainable

agriculture objectives and cooperation and coordination among them.

- Sufficient and proper credits for sustainable production

5 - Orientation of administrative organizations such as ministry of agriculture towards sustainable agriculture in all levels.

-Living status of consumers and their culture for using healthy products are also important factors.

- integrating lands and prevention from separation of existing lands cooperation and interaction between

researchers, extension workers, farmers and policy-markers

6 - To make state aids meaningful in order to increase motive for using sustainable methods

$\frac{7 \quad-\text { Reform of agricultures governmental structure }}{\text { Note: Level of agreement set a priori at } 80 \% \text { to retain effective factor }}$

Table 4: The factors influential in achieving sustainable agriculture can be categorized in 7 groups

\begin{tabular}{|c|c|}
\hline Categories & Cases \\
\hline Policy-making & $\begin{array}{l}\text { Effort for being competent from scientific viewpoint (utilization of specialized human resources in state and private } \\
\text { departments, giving facilities such as credits to specialists) } \\
\text { Explanation of government's policies for agriculture } \\
\text { Adoption of sustainable agriculture strategy in huge Policies } \\
\text { Reform of macro and micro management in agriculture affairs } \\
\text { Establishment of powerful and required organizational structures and cooperation and coordination between them for } \\
\text { achieving sustainable agriculture } \\
\text { Codification and/or amendment of regulations for executing or non- executing sustainable agriculture methods } \\
\text { To make state aids meaningful to achieve sustainable agriculture } \\
\text { Formation of agriculture interactive, logical and elastic programming system } \\
\text { Reform of agriculture's governmental structure for achieving sustainable agriculture }\end{array}$ \\
\hline Infrastructure & $\begin{array}{l}\text { Creation and development of production infrastructures among them field structures } \\
\text { Creation of efficient irrigational systems } \\
\text { Promotion of mechanization } \\
\text { Provision of special machinery or equipments for Sustainable agriculture for farmers and easy access to them } \\
\text { Unification of lands and prevention from separation of them } \\
\text { Proper marketing for development of export of sustainable agriculture products }\end{array}$ \\
\hline Researches & Attention of research organizations to required researches about sustainable agriculture \\
\hline Education & $\begin{array}{l}\text { Education and explanation of sustainable agriculture's concepts for all society from producers to consumer } \\
\text { Effective education to make farmers powerful Education and training of specialized human forces to execute sustainable } \\
\text { agriculture }\end{array}$ \\
\hline Extension & $\begin{array}{l}\text { Utilization of techniques and methods which are proportional for farmers achieve sustainable agriculture such as utilization } \\
\text { of farmer field schools and co-operational approaches } \\
\text { Invention of an efficient system to give information to Farmers about sustainable agriculture } \\
\text { Presentation of modern patterns in sustainable agriculture to researchers, policy-maker and specially farmers } \\
\text { Reinforcement to extension section and settlement to extension workers in farms } \\
\text { Definition and Presentation of criteria and indicators for Sustainable agriculture }\end{array}$ \\
\hline Economical & $\begin{array}{l}\text { Sufficient and proper credits for sustainable production } \\
\text { Improvement of economical status of consumers (elimination of poverty) for using sustainable agriculture, s products } \\
\text { Sufficient and required credits to produce and manufacture compatible plants with sustainable agriculture } \\
\text { Attention to invention in agriculture section and absorption of foreign capitals }\end{array}$ \\
\hline Social & Cultural development to execute sustainable agriculture methods \\
\hline
\end{tabular}


Table 4: continuous

Utilization of motives in order to excite farmers for executing sustainable agriculture

Cultural development to use healthy products by consumers

Validation of sustainable agriculture, s products

Cooperation Interactive and cooperation between researchers, Promoters, farmers and policy-makers

The third phase ( Table 3) demonstrates the amount of experts' agreement to the effective factors. Response rates at this stage were $66 / 07 \%$. The researchers had more than $80 \%$ agreement to all factors. So as Robert and Dyer, (2004) expressed that any factor with less than about $80 \%$ of experts agreement should be deleted, there were no such case observed in this study. The findings of the third stage of the Delphi method reveal that the factors which received $100 \%$ consensus by the experts, taking into account the conditions prevalent in Iran, are as follows: In order to achieve sustainable agriculture in Iran, large-scale research is required; communication, interaction and cooperation between researchers, extension experts, farmers and organizers are necessary; attempting to develop scientific. Approaches and creating an interactional, reasonable, flexible planning system are among other influential factors.

The second objective of the study sought to categorize the effective factors in achieving sustainable agriculture into a working model. In this model seven categories were identified as effective factor in achieving sustainable agriculture. As indicated in Table 4, factors identified in round three were categorized into Policy-making, Infrastructure, Researches, Education, Extension, Economical, Social, and Cooperation.

\section{DISCUSSION}

According to the findings, research institutions should pay more attention to the research needed to drive sustainable agriculture. Several studies considered the importance and role of research institutions to achieve sustainable agriculture (Katsuyuki, 1997; Salmanzadeh, 1996; Reeves, 1997). It is important for researchers, extension workers, farmers and policymakers in the executive systems to have the interactions and contributions for achieving sustainable agriculture. the administrative systems in Iran have a relatively weak interaction and participation in this respect.

Swanson (1996) researching in the field of relationships of research- extension- farmer states that the lack of working relationships between these organizations is one of the most intricate problems of institutional ministries of agriculture in many developing countries (Karami, 1995). In fact, one can not take measures to achieve sustainable agriculture without considering the role of government and its policies in this field.

The results of this research conform what other researcher have expressed (Pretty, 2003; Katsuyuki, 1997; Roling and Pretty, 1996; Salmanzadeh, 1996).

\section{CONCLUSION}

There were two objectives for this study, so two conclusions were drawn. The first objective of this study was to identify the effective factors in achieving sustainable agriculture 35 effective factors exist (Table 1).

The second objective was to categorize the effective factors in achieving sustainable agriculture. effective factors in achieving sustainable agriculture can be categorized into Policy-making, Infrastructure, Researches, Education, Extension, Economical, Social, and Cooperation.

Based on what was expressed, it can be concluded that for implementing the sustainable agricultural methods in the fields of Iran:

- It is essential that the communication between extension, farmers and policymaker should be strengthen. So extension organizations should attempt to promote working relationships with research institutions, NGOs, agricultural institutions and decision-making systems of policymakers and putting efforts to use participatory approaches in this respect

- Policy and instructions of research institutions should be in line with related field of research is sustainable production. In this context, the proposed model of reeve (1998) can be used (Reeves, 1997)

- What is important in this field is to emphasize and motivate human resources. Because as long as human and his psychological aspects are neglected, his efficiency in different fields cannot be considered helpful. Thus, democracy should be the focused on in academic programs and administrative policies, particularly in different parts of research, extension and education

- Iran's agricultural planning system must be transformed and planning should be interactive, 
reasonable and flexible. Therefore, compiling, designing and implementing such programs should be in partnership with researchers, extension workers, farmers and policymakers

- The policymakers of agricultural system should be strong and possess support policy too

- Formal and informal education system should serve the promotion of knowledge and awareness to achieve their husbandry and sustainable agriculture. In addition, extension institutions must use all of their resources in the path leading to sustainable agriculture

- Improving the economic conditions of people, especially farmers and consumers, seems to be a key factor achieving sustainable agriculture. Paying attention to this factor should be one of the most important concerns of agricultural policies

\section{REFERENCES}

Swanson, B.E., 1996. Strengthen the Relationship between Research-Extension-Farmer. Improving Agriculture Extension: A Reference Manual, B.E. Swanson et al., Eds., ISBN: 964-6597-11-4, pp: 471-490.

Karami, E., 1995. Agricultural extension: The question of sustainable development in Iran. J. Sust. Agr., 5: 61-72. DOI: 10,1300/1064705n01_05

Pretty, J.N., 2003. Regenerating Agriculture: Policies and Practice for Sustainable and Self-Reliance. Tehran, Farazan, ISBN: 964-90708-4-2, pp: 555.

Katsuyuki, M., 1997. How to Achieve Sustainable Agriculture, Appropriate Use of Inputs for Sustainable Agriculture. www.niaes.affirc.go.jp/annual/r1997/html/p33-p34.htm

Malakooti, M., 2003. Agricultural Products without Nitrite and Cadmium: A Valuable Step toward Food Security of the Society. Technical paper, No. 328, Khaniran Publications, Tehran.
Malakooti, M., 2005. Sustainable Agriculture and Performance Enhancement by optimized Use of Fertilizers in Iran. Sana, ISBN: 964-8871-06-x, pp: 496.

Dalkey, N.C., 1969. The Delphi Method: An Experimental Study of Group Opinion. Santa Monica: The Rand Corporation. http://oai.dtic.mil/oai/oai?verb=getRecord\&metada taPrefix $=$ html\&identifier $=$ AD0690498

Roling, N. and J.N. Pretty, 1996. Extension Role in Sustainable Agriculture Development. Improving Agricultural Extension: A Reference Manual, B.E. Swanson et al., Eds., ISBN: 964-6597-11-4, pp: 471-490.

Report of Ministry of Agriculture, 2001. Sustainable Agriculture Strategy on Executive sections of Iran. Sustainable Development national commission.

Report of University of Tehran's Research Deputy, 2000. Final Report on factors of Sustainable Agricultural Development, Measurement Methodology and instructions for their application in Garmsar, Iran. Institute for Agricultural Economics and Planning Research, Tehran, pp: 435.

Salmanzadeh, S. 1996, Sustainable Agriculture in Approach and Mission to promote Agricultural Development in Iran. Proceeding of the 6th Seminar on Scientific Agricultural Extension, Mashhad Ferdowsi University, pp: 37.

Reeves, T.G., 1997. Sustainable Intensification of Agriculture. http://www.cimmyt.mx/whatiscmmyt/Sust $1 \mathrm{nt} . \mathrm{htm}$

Roberts, T.G. and J.E. Dyer, 2004. Characteristics of effective agriculture teachers. J. Agri. Edu., 45: 82-95. 